\title{
ANÁLISE DOS EFEITOS IONOSFÉRICOS DE ORDEM SUPERIOR NO CICLO SOLAR 24 E INFLUÊNCIA NO POSICIONAMENTO GNSS ABSOLUTO
}

Analysis of higher order ionospheric effects in the solar cycle 24 and influence in the GNSS absolute positioning

\author{
HAROLDO ANTONIO MARQUES ${ }^{1}$ \\ JOÃO FRANCISCO GALERA MONICO ${ }^{2}$ \\ HELOÍSA ALVES SILVA MARQUES ${ }^{3}$ \\ MÁRCIO AQUINO ${ }^{4}$
}

${ }^{1}$ Universidade Federal de Pernambuco-UFPE / Centro de Tecnologia e Geociências

Departamento de Engenharia Cartográfica, Recife - PE - Brasil

haroldoh2o@gmail.com

${ }^{2}$ Universidade Estadual Paulista-UNESP / Faculdade de Ciências e Tecnologia

Pós Graduação em Ciências Cartográficas

Departamento de Cartografia, Presidente Prudente - SP

galera@fct.unesp.br

${ }^{3}$ Instituto Militar de Engenharia-IME

Seção de Ensino de Engenharia Cartográfica, Rio de Janeiro - RJ - Brasil

heloh2o@gmail.com

${ }^{4}$ University of Nottingham / Nottingham Geospatial Institute

University Park - Nottingham - UK

marcio.aquino@nottingham.ac.uk

\begin{abstract}
RESUMO
A aplicação da combinação livre da ionosfera para dados GNSS de dupla frequência permite eliminar matematicamente os efeitos de primeira ordem da ionosfera. Contudo, os efeitos de ordem superior não são eliminados e, geralmente, são negligenciados no processamento dos dados GNSS. Neste trabalho apresentam-se discussões e análises relacionadas ao cálculo dos efeitos de ordem superior da ionosfera, o qual envolve o cálculo do TEC a partir de diferentes combinações, o sistema geomagnético IGRF-11, a combinação linear livre da ionosfera para tripla
\end{abstract}


frequência considerando as três portadoras do GPS (L1, L2 e L5) e outras. A combinação de tripla frequência permite eliminar o efeito de segunda ordem da ionosfera, contudo, a incerteza propagada desta combinação é de pior qualidade do que o próprio valor do efeito. Foram realizados processamentos de dados no modo PPP estático e cinemático visando avaliar a influência dos efeitos de ordem superior no ciclo solar 24. Os dados GPS foram corrigidos dos efeitos ionosféricos utilizando o software "RINEX_HO" disponível no NGS-NOAA-TOOLBOX. Os resultados mostraram que a negligência dos efeitos ionosféricos de ordem superior no PPP pode provocar variações da ordem de milímetros a centímetros considerando períodos com baixa e alta atividade ionosférica, respectivamente.

Palavras-chave: Efeitos Ionosféricos de Ordem Superior; Combinação de Tripla Frequência; PPP; Ciclo Solar.

\section{ABSTRACT}

The application of the ionosphere free combination for GNSS dual frequency data allows mathematically the elimination of the first order ionosphere effects. However, the higher order ionosphere effects are not eliminated and are generally neglected in GNSS data processing. In this paper, there will be discussions and analysis related to the higher order ionospheric effects computation which involves calculating TEC from different combinations, the geomagnetic reference system IGRF-11, the ionosphere free linear combination for three GPS frequencies L1, L2 and L5 and other. The triple frequency combination allows eliminating the second order effect, however the propagated precision of the combination is worse than the value of the effect itself. It was accomplished data processing in the static and kinematic PPP aiming to evaluate the influence of the higher order effects in the solar cycle 24.The GPS data were corrected from higher order effects by using the "RINEX_HO" software available in the NGS-NOAA-TOOLBOX. The results showed that neglecting the higher order effects in the PPP can produce variations of the order of millimeters to centimeters considering periods with low and high ionosphere activity, respectively.

Keywords: Higher Order Ionosphere Effects; Triple Frequency Combination; PPP; Solar Cycle.

\section{INTRODUÇÃO}

Os efeitos ionosféricos representam atualmente uma das maiores fontes de erros envolvidos com a propagação dos sinais GNSS (Global Navigation Satellite System) e precisam ser modelados adequadamente para realização de posicionamento geodésico com precisão milimétrica. Os satélites GNSS em sua concepção original transmitem sinais de rádios em duas frequências, cujo objetivo principal é permitir a correção dos efeitos de primeira ordem da ionosfera, o que pode ser feito a partir da combinação livre da ionosfera. Contudo, os efeitos de segunda e terceira ordem da ionosfera (efeitos de ordem superior) não são 
eliminados e, geralmente, são negligenciados no processamento dos dados GNSS, o que implica em efeitos residuais na estimativa das coordenadas geodésicas.

$\mathrm{O}$ atraso no sinal causado pelo efeito de primeira ordem representa em torno de 99\% do efeito total, ficando o restante a cargo dos efeitos de ordem superior da ionosfera. Logo, para muitos tipos de aplicações práticas, os efeitos ionosféricos de ordem superior não representam maiores problemas, porém, para aplicações científicas ou que requeiram resultados com alta precisão, tal como a materialização de referenciais geodésicos, a não correção dos efeitos de ordem superior implica em efeitos residuais nas coordenadas da ordem de milímetros podendo chegar a centímetros (FRITSCHE et al., 2005; IERS, 2010). Neste sentido, pesquisas a nível internacional têm sido conduzidas nos últimos anos visando o estudo e forma adequada de modelar os efeitos ionosféricos de ordem superior (FRITSCHE et al., 2005; PAJARES et al., 2007; IERS, 2010; ELMAS et al., 2011; FERNANDEZ et al., 2013).

Com base nas principais pesquisas realizadas ao redor do mundo, o IERS (International Earth Rotation and Reference System) recomenda através do IERS Conventions (2010) que os centros de processamento de dados do ITRF (International Terrestrial Reference Frame) apliquem as correções dos efeitos ionosféricos de ordem superior. Dentro deste contexto, um trabalho foi desenvolvido no Brasil por Marques (2011), o qual investigou e implementou a formulação matemática envolvida com a correção dos efeitos de ordem superior da ionosfera, culminando na produção de um software denominado "RINEX_HO" para correção destes efeitos nas observáveis GPS via arquivos RINEX. Este software encontra-se, atualmente disponível com código fonte na homepage do NGS-NOAATOOLBOX (https://www.ngs.noaa.gov/gps-toolbox/RINEX_HO.htm).

Nesta contribuição apresentam-se discussões relacionadas a modelagem matemática dos efeitos de ordem superior da ionosfera envolvendo o cálculo do TEC (Total Electron Content) a partir de diferentes métodos, obtenção das componentes no sistema geomagnético com a utilização de um sistema mais realista através do IGRF (International Geomagnetic Reference Field), a combinação linear entre as três portadora (L1, L2 e L5), além de outras. É importante destacar que com a modernização do GPS atualmente tem-se sete satélites do bloco IIF transmitindo dados na terceira portadora (L5), além de diversos satélites com o novo código civil na L2 (L2C). A combinação de tripla frequência permite eliminar matematicamente os efeitos de segunda ordem, contudo a incerteza propagada desta combinação é naior do que o próprio valor do efeito ionosférico de segunda ordem, de forma que a utilização de modelos matemáticos alternativos para a correção destes efeitos pode proporcionar melhores resultados. Foram realizados processamentos de dados GPS no modo PPP (Posicionamento Por Ponto Preciso) estático e cinemático utilizando o software "RT_PPP" desenvolvido por Marques (2012) envolvendo dados da região brasileira no período do ciclo solar 24. Os resultados mostram que a negligência dos efeitos ionosféricos de ordem superior no PPP pode provocar variações nas 
coordenadas estimadas da ordem de milímetros a centímetros em períodos com baixa e alta atividade ionosférica, respectivamente.

\section{EFEITOS DA IONOSFERA NO SINAL GNSS}

Em termos de posicionamento geodésico, o parâmetro da ionosfera que produz a maioria dos efeitos nos sinais GPS é o conteúdo total de elétrons livres na ionosfera, denominado TEC, o qual é definido como o número de elétrons em uma coluna vertical com um metro quadrado de sessão transversal estendendo sobre todo o caminho do satélite GPS até o receptor (KLOBUCHAR, 1996).

As variações temporais da ionosfera compreendem as diurnas, sazonais e ciclos de longos períodos e que influenciam diretamente na mudança da densidade de elétrons na ionosfera. As variações diurnas são provocadas por mudanças que ocorrem em certas regiões da ionosfera principalmente devido à iluminação do sol, ou seja, a variação da radiação solar durante o dia (MATSUOKA, 2007). A variação sazonal ocorre durante os meses do ano em uma determinada região devido à variação sazonal do ângulo zenital do Sol e também devido às mudanças intrínsecas da camada ionosférica. As variações de ciclos de longos períodos na densidade de elétrons, com ciclos de aproximadamente 11 anos, são associadas às ocorrências de manchas solares (sunspot). O aumento do número de manchas solares aumenta a radiação solar e ocasiona uma mudança na densidade de elétrons na ionosfera. A Figura 1 mostra o histórico dos ciclos solares (número de manchas) desde 1700 até atualmente.

Figura 1 - Histórico do número de manchas solares (ciclos solares).

Fonte: http://sidc.oma.be/silso/datafiles (Acesso em: fev. 2014).

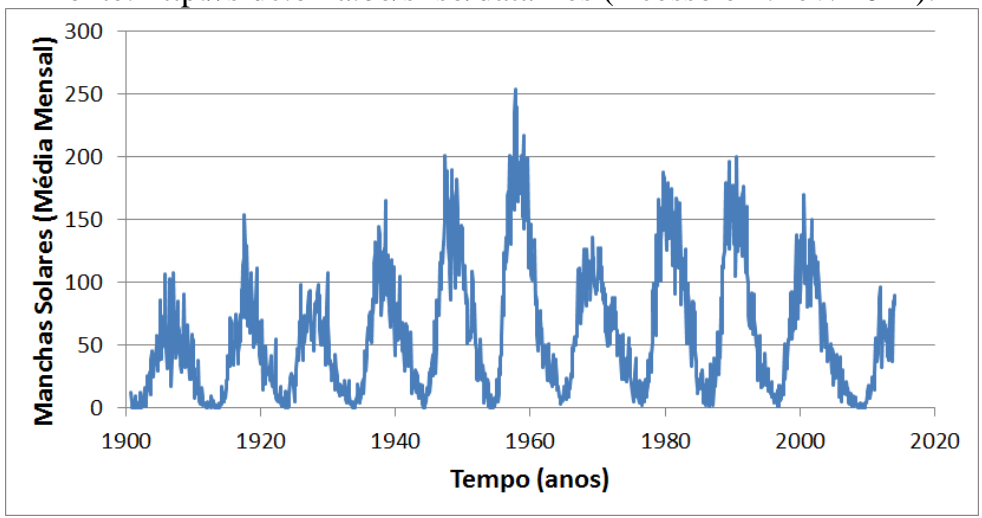

O último pico do número de manchas solares no ciclo 23 ocorreu em meados do ano 2000. A predição de máximo pico para o ciclo solar 24 foi inicialmente para meados do ano 2013, contudo, o máximo número de manchas solares observada até o momento ocorreu em fevereiro de 2012 com uma suavização no ano de 2013. As 
observações juntamente com a predição de manchas solares têm feito do ciclo solar 24 um dos ciclos de menor amplitude desde o ciclo de número 14 que ocorreu em 1906 (NASA, 2014).

O efeito da refração atmosférica sobre a propagação de ondas eletromagnéticas entre o satélite e o receptor pode ser avaliado usando o princípio de Fermat, o qual diz que "de todos os caminhos possíveis, a luz e outras ondas EM (eletromagnéticas) percorrem o caminho que leva o menor tempo" (ODIJK, 2002). No espaço livre a onda se propaga em linha reta, mas no meio refrativo ela sofre uma curvatura, como mostrado na Figura 2.

Figura 2 - Desvio do sinal através da atmosfera refrativa.

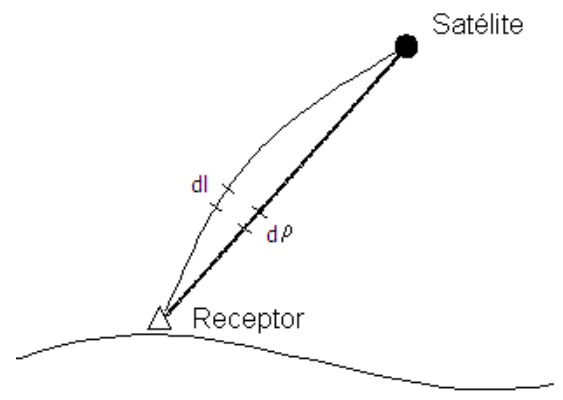

$\mathrm{O}$ índice refrativo do meio para a fase $\mathrm{n}_{\phi}$ pode ser definido pela razão entre a velocidade da luz e a velocidade da fase $v_{\phi}$, e da mesma forma para índice de refração do grupo $\mathrm{n}_{\mathrm{g}}$, porém usando a velocidade de grupo $v_{\mathrm{g}}$.

$$
\mathrm{n}_{\phi}=\frac{\mathrm{c}}{v_{\phi}} \quad \text { e } \quad \mathrm{n}_{\mathrm{g}}=\frac{\mathrm{c}}{v_{\mathrm{g}}} .
$$

Considerando o índice de refratividade e da velocidade da fase, o comprimento do caminho óptico entre o satélite e o receptor é calculado por (ODIJK, 2002):

$$
\ell_{\phi}=\mathrm{ct}_{\phi}=\mathrm{c} \int \mathrm{dt}_{\phi}=\int \frac{\mathrm{c}}{v_{\phi}} \mathrm{dl}_{\phi}=\int \mathrm{n}_{\phi} \mathrm{dl}_{\phi}=\rho+\underbrace{\int\left(\mathrm{n}_{\phi}-1\right) \mathrm{d} \rho}_{\vartheta_{\phi}}+\underbrace{\left.\int \mathrm{n}_{\phi} \mathrm{dl}_{\phi}-\int \mathrm{n}_{\phi} \mathrm{d} \rho\right)}_{\mathrm{\kappa}_{\phi}},
$$

em que, $\rho$ denota a distância geométrica entre o satélite (no instante de transmissão) e o receptor (no instante de recepção). O excesso no comprimento do caminho consiste de dois efeitos: o efeito de propagação, denotado por $\vartheta_{\phi}$ e o efeito de curvatura, denotado por $\kappa_{\phi}$. As equações dos excessos do grupo são obtidas da 
mesma forma que para a fase. A relação entre a velocidade de grupo $v_{\mathrm{g}}$ e a velocidade da fase $v_{\phi}$, bem como a relação entre o índice de refração do grupo e da fase, são obtidas a partir da equação de Rayleigh:

$$
v_{g}=v_{\phi}+f \frac{\partial v_{\phi}}{\partial f} \quad \text { e } \quad n_{g}=n_{\phi}+f \frac{\partial n_{\phi}}{\partial f}
$$

as quais são úteis na determinação do índice refrativo ionosférico.

\section{1 Índice de Refratividade da Ionosfera}

O índice refrativo da fase na ionosfera é dado pela fórmula complexa de Appleton-Hartree. Considerando uma onda EM viajando em um sistema ortogonal de eixos $\mathrm{X}, \mathrm{Y}$ e Z e, ignorando os efeitos de absorção devido às colisões entre os elétrons, essa fórmula é dada por (DAVIES, 1990):

$$
\mathrm{n}_{\phi \pm}^{\text {iono }}=\sqrt{1-\frac{\mathrm{X}}{1-\frac{\mathrm{Y}_{\mathrm{T}}^{2}}{2(1-\mathrm{X})} \pm \sqrt{\frac{\mathrm{Y}_{\mathrm{T}}^{4}}{4(1-\mathrm{X})^{2}}+\mathrm{Y}_{\mathrm{L}}^{2}}}},
$$

em que, $X=\frac{f_{p}^{2}}{f^{2}}$ e $Y=\frac{f_{g}}{f}, Y_{T}$ e $Y_{L}$ são as componentes transversal e longitudinal de $\mathrm{Y}$. Então, $\mathrm{Y}_{\mathrm{T}}=\mathrm{Y}|\operatorname{sen} \theta|$ e $\mathrm{Y}_{\mathrm{L}}=\mathrm{Y}|\cos \theta|$, onde $\theta$ é o ângulo entre $\mathrm{Y}$ e $\mathrm{Y}_{\mathrm{L}}$.

A frequência $\mathrm{f}_{\mathrm{p}}$ é conhecida como a frequência de plasma do elétron, que é a frequência natural de oscilação para a superfície (slab) do plasma neutro, após os elétrons serem removidos de seus íons e capazes de se mover livremente. Essa frequência é calculada a partir de:

$$
\mathrm{f}_{\mathrm{p}}=\sqrt{\mathrm{AN}_{\mathrm{e}}}, \quad \operatorname{com} \mathrm{A}=\frac{\mathrm{e}^{2}}{4 \pi \mathrm{m}_{\mathrm{e}} \varepsilon_{0}} \approx 80,6 \mathrm{~m}^{3} / \mathrm{s}^{2},
$$

em que, $\mathrm{N}_{\mathrm{e}}$ é a densidade de elétrons livres em $\mathrm{m}^{-3}$, e = 1,60218.10 ${ }^{-19}$ Coulomb para a carga do elétron, $\mathrm{m}_{\mathrm{e}}=9,10939.10^{-31} \mathrm{~kg}$ para a massa do elétron e $\varepsilon_{0}=8,85419.10^{-12}$ Farad/metro para a permissividade do espaço livre. A frequência $\mathrm{f}_{\mathrm{g}}$ é conhecida como girofrequência (gyrofrequency) ou frequência de giro, a qual é definida como a frequência natural onde os elétrons livres circulam ao redor das linhas do campo geomagnético. Essa frequência é calculada como (DAVIES, 1990): 


$$
\mathrm{f}_{\mathrm{g}}=\frac{\mathrm{e}}{2 \pi \mathrm{m}_{\mathrm{e}}} \mathrm{B}
$$

em que, B denota o vetor do campo geomagnético.

$\mathrm{O}$ sinal \pm na equação de Appleton-Hartree (Equação 4), reflete a dupla refração da onda EM, no qual o "+” corresponde à onda polarizada circularmente a esquerda (onda extraordinária) e o "-" corresponde à onda polarizada circularmente a direita (onda ordinária). Para o GNSS, somente a onda ordinária é significante, logo, utiliza-se o sinal de menos para o índice refrativo. $O$ índice de refração ionosférico expandido na série de Taylor de $\mathrm{X}$ e $\mathrm{Y}$ pode ser representado por:

$$
\mathrm{n}_{\phi}^{\text {iono }}=1-\frac{1}{2} \mathrm{X}-\frac{1}{2}|\cos \theta| \mathrm{XY}-\frac{1}{8} \mathrm{X}^{2}+\mathrm{R}_{3},
$$

em que, $\mathrm{R}_{3}$ representa termos de ordem superior da série. A magnitude ou os termos da série de Taylor são dados por:

$$
\frac{1}{2} \mathrm{X} \sim 10^{-5}, \quad \frac{1}{2}|\cos \theta| \mathrm{XY} \sim 10^{-8} \text { e } \frac{1}{8} \mathrm{X}^{2} \sim 10^{-10},
$$

na qual nota-se que o tamanho de $\mathrm{R}_{3}$ na série de Taylor é da ordem de $10^{-10}$, o que contribui para a observação da fase a um nível submilimétrico. Dessa forma, com o auxílio dos intervalos acima (Equação 8) e da relação entre o índice de refração do grupo e da fase apresentado (Equação 3), o índice de refração da ionosfera para a fase e para o grupo, pode ser aproximado por (ODIJK, 2002):

$$
\begin{aligned}
& \mathrm{n}_{\phi,}^{\text {iono }}=1-\frac{1}{2} \frac{\mathrm{f}_{\mathrm{p}}^{2}}{\mathrm{f}^{2}}-\frac{1}{2} \frac{\mathrm{f}_{\mathrm{p}}^{2} \mathrm{f}_{\mathrm{g}}|\cos \theta|}{\mathrm{f}^{3}}-\frac{1}{8} \frac{\mathrm{f}_{\mathrm{p}}^{4}}{\mathrm{f}^{4}} \\
& \mathrm{n}_{\mathrm{g},}^{\text {iono }}=1+\frac{1}{2} \frac{\mathrm{f}_{\mathrm{p}}^{2}}{\mathrm{f}^{2}}+\frac{\mathrm{f}_{\mathrm{p}}^{2} \mathrm{f}_{\mathrm{g}}|\cos \theta|}{\mathrm{f}^{3}}+\frac{3}{8} \frac{\mathrm{f}_{\mathrm{p}}^{4}}{\mathrm{f}^{4}}
\end{aligned}
$$

Verifica-se então, que o índice de refração para a fase é sempre menor que 1, enquanto que o mesmo não ocorre para o índice do grupo, o que reflete o avanço da fase e o atraso do grupo do sinal GNSS na ionosfera.

\subsection{Efeitos Ionosféricos de Primeira, Segunda e Terceira Ordem da Ionosfera}

O desenvolvimento das equações para levar em consideração os efeitos de ordem superior da ionosfera nas observáveis GPS, bem como discussões relacionadas ao assunto, podem ser encontrados em Bassiri e Hajj (1993), Odijk (2002), Kedar et al. (2003), Pajares et al. (2005), Marques et al. (2011), dentre 
outros. Para obter as equações dos efeitos de propagação de primeira, segunda e terceira ordem da ionosfera é necessário usar o índice de refração da ionosfera (Equação 9), o qual ao ser inserido na Equação 2 permite obter o efeito de propagação do sinal para a fase e para o grupo ( $\vartheta_{\phi}^{\text {iono }}$ e $\vartheta_{\mathrm{g}}^{\text {iono }}$ ) (ODIJK, 2002):

$$
\begin{aligned}
\vartheta_{\phi}^{\text {iono }} & =\int\left(1-\frac{1}{2} \frac{\mathrm{f}_{\mathrm{p}}^{2}}{\mathrm{f}^{2}}-\frac{1}{2} \frac{\mathrm{f}_{\mathrm{p}}^{2} \mathrm{f}_{\mathrm{g}}|\cos \theta|}{\mathrm{f}^{3}}-\frac{1}{8} \frac{\mathrm{f}_{\mathrm{p}}^{4}}{\mathrm{f}^{4}}-1\right) \mathrm{d} \rho \\
& =-\underbrace{\frac{1}{2 \mathrm{f}^{2}} \int \mathrm{f}_{\mathrm{p}}^{2} \mathrm{~d} \rho}_{\mathrm{I}_{\phi}^{(1)}}-\underbrace{\frac{1}{2 \mathrm{f}^{3}} \int \mathrm{f}_{\mathrm{p}}^{2} \mathrm{f}_{\mathrm{g}}|\cos \theta| \mathrm{d} \rho}_{\mathrm{I}_{\phi}^{(2)}}-\underbrace{\frac{1}{8 \mathrm{f}^{4}} \int \mathrm{f}_{\mathrm{p}}^{4} \mathrm{~d} \rho}_{\mathrm{I}_{\phi}^{(3)}}, \\
& =\int\left(1+\frac{1}{2} \frac{\mathrm{f}_{\mathrm{p}}^{2}}{\mathrm{f}_{\mathrm{j}}^{2}}+\frac{1}{2} \frac{\mathrm{f}_{\mathrm{p}}^{2} \mathrm{f}_{\mathrm{g}}|\cos \theta|}{\mathrm{f}_{\mathrm{j}}^{3}}+\frac{3}{8} \frac{\mathrm{f}_{\mathrm{p}}^{4}}{\mathrm{f}_{\mathrm{j}}^{4}}-1\right) \mathrm{d} \rho \\
& =\underbrace{\frac{1}{2 \mathrm{f}^{2}} \int \mathrm{f}_{\mathrm{p}}^{2} \mathrm{~d} \rho}_{\mathrm{I}_{\mathrm{g}}^{(1)}}+\underbrace{\frac{1}{\mathrm{f}^{3}} \int \mathrm{f}_{\mathrm{p}}^{2} \mathrm{f}_{\mathrm{g}}|\cos \theta| \mathrm{d} \rho}_{\mathrm{I}_{\mathrm{g}}^{(2)}}+\underbrace{\frac{3}{8 \mathrm{f}^{4}} \int \mathrm{f}_{\mathrm{p}}^{4} \mathrm{~d} \rho}_{\mathrm{I}_{\mathrm{g}}^{(3)}}
\end{aligned}
$$

Inserindo as Equações 5 e 6 das frequências de plasma e de giro do elétron $\left(f_{p}\right.$ e $f_{g)}$ nas Equações 10 e 11, os efeitos de primeira ( $\left.I_{g}^{(1)}\right)$, segunda $\left(I_{g}^{(2)}\right)$ e terceira ( $\mathrm{I}_{\mathrm{g}}^{(3)}$ ) ordem para o caso do grupo são dados por (ODIJK, 2002; IERS, 2010):

$$
\begin{aligned}
& I_{g}^{(1)}=\frac{A}{2 f^{2}} \int N_{e} d \rho=\frac{A}{2 f^{2}} \text { STEC } \\
& I_{g}^{(2)}=\frac{e A}{f^{3} 2 \pi m_{e}} \int B \cdot \cos \theta \cdot N_{e} d \rho=\frac{e A}{f^{3} 2 \pi m_{e}} B \cdot \cos \theta \cdot S T E C . \\
& I_{g}^{(3)}=\frac{3 A}{8 f^{4}} \int N_{e}^{2} d \rho=\frac{3 \cdot A^{2}}{8 \cdot f^{4}} \eta N_{e, \max } \text { STEC }
\end{aligned}
$$

No conjunto de Equações 12, pode ser visto que o atraso ionosférico é uma função do termo $\int \mathrm{N}_{\mathrm{e}} \mathrm{d} \rho$, o que representa o STEC (Slant TEC) ao longo da linha geométrica do receptor até o satélite. O efeito de segunda ordem é dependente do vetor de propagação no campo geomagnético e devido ao termo quadrático na equação do efeito de terceira ordem comparece a densidade máxima de elétrons $\mathrm{N}_{\mathrm{e}, \max }$ e o fator $\eta$, cujo valor constante é igual a 0,66 (HATMANN; LEITINGER, 
1984 apud ODIJK, 2002). A densidade máxima de elétrons $\mathrm{N}_{\mathrm{e}, \max }$ pode ser calculada com base no modelo ionosférico desenvolvido por Brunner e Gu (1991) e adaptado por Fritsche et al. (2005).

\subsection{Campo Geomagnético Considerado Real}

Discussões sobre a utilização do campo magnético baseado no modelo dipolar ou em um modelo mais realístico podem ser encontradas em Pajares et al. (2005) ou Marques et al. (2009). Devido ao campo magnético da Terra ser um campo vetorial, a medição de sua amplitude requer as medidas dos ângulos de declinação e inclinação ou a medição de suas três componentes num referencial conhecido. É comum usar um referencial cartesiano local para cada ponto de observação como mostrado na Figura 3:

Figura 3 - Vetores componentes e ângulos associados com o campo geomagnético. Adaptado de SCHUNK; NAGY (2000).

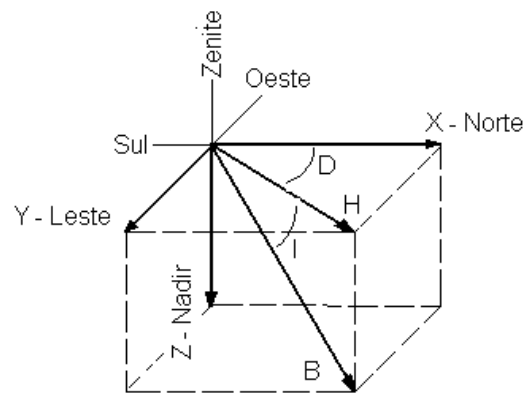

Na Figura 3 o ângulo $\mathrm{D}=\tan ^{-1}(\mathrm{Y} / \mathrm{X})$ é a declinação, que é a deflexão do campo geomagnético a partir do pólo geográfico. O ângulo $\mathrm{I}=\tan ^{-1}(\mathrm{Z} / \mathrm{H})$ é o ângulo de inclinação (dip angle) do campo geomagnético. A componente $\mathrm{B}$ representa a magnitude do campo magnético, $\mathrm{H}$ é a amplitude da componente horizontal e as componentes cartesianas de B, seguem as direções Norte-Sul para $\mathrm{X}=\mathrm{H} \cos (\mathrm{D})$, Leste-Oeste para $\mathrm{Y}=\mathrm{Hsen}(\mathrm{D})$ e $\mathrm{Z}$ representa a componente vertical. O cálculo de B é dado por (SCHUNK; NAGY, 2000):

$$
\mathrm{B}=\sqrt{\left(\mathrm{H}^{2}+\mathrm{Z}^{2}\right)} \text { com } \mathrm{H}=\sqrt{\left(\mathrm{X}^{2}+\mathrm{Y}^{2}\right)} .
$$

O sistema de eixos como mostrado na Figura 3 deve ser obtido no ponto ionosférico (pierce point) na altura da camada ionosférica. Desde o ano de 1945, o IGRF vem desenvolvendo um modelo para a representação do campo magnético da Terra, o qual é recomendado para trabalhos científicos pelo grupo IAGA 
(International Association of Geomagnetism and Aeronomy). O modelo do IGRF consiste de um conjunto de coeficientes harmônicos esféricos globais, os quais geralmente são válidos para um período de cinco anos. Esse período de validade é escolhido levando em consideração as variações intrínsecas do campo magnético. Atualmente, encontra-se disponível o modelo IGRF-11 (IAGA, 2014). O código fonte em Fortran para o cálculo dos componentes do campo geomagnético pode ser encontrado em http://www.ngdc.noaa.gov/IAGA/vmod/igrf11.f (Acesso em 2014).

Utilizando as equações apresentadas na seção anterior foram calculados os efeitos de segunda ordem da ionosfera na L1 (I2_L1) utilizando o modelo dipolar e o modelo IGRF-11 para diversas estações da rede IGS (International GNSS Service) espalhadas ao redor do planeta. A Figura 4 mostra as diferenças obtidas ao comparar os máximos valores de I2_L1 ao longo do dia ao utilizar os dois modelos de campo geomagnético.

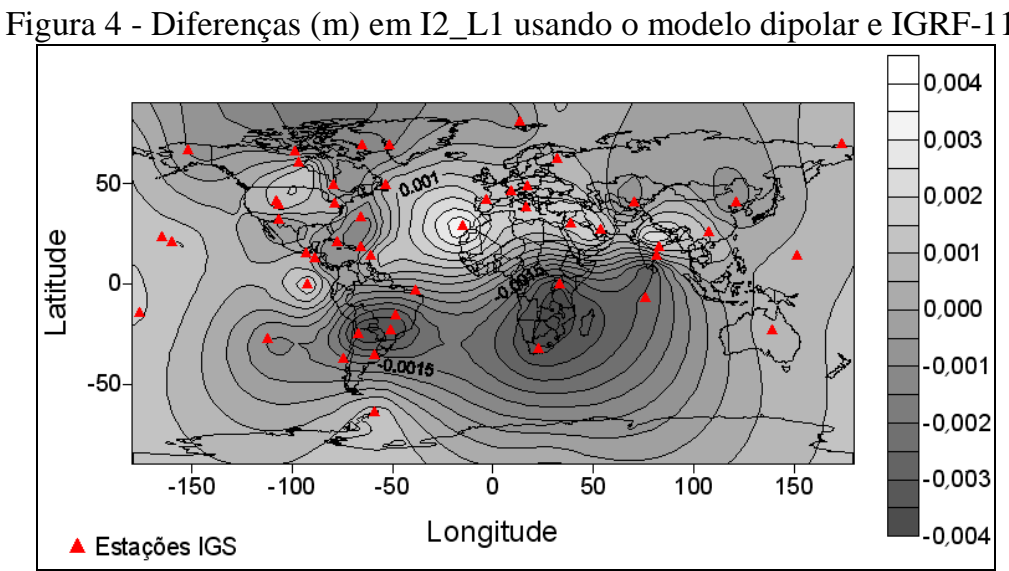

Verifica-se a partir da Figura 4 que as máximas diferenças encontradas ocorrem ao longo do Equador terrestre e atingem a ordem de aproximadamente 4 $\mathrm{mm}$. A magnitude dos efeitos ionosféricos de segunda ordem na L1 calculados no experimento atingiram no máximo $8 \mathrm{~mm}$ ao longo do dia para algumas estações da rede IGS, de maneira que as discrepâncias atingem a ordem de $50 \%$ ao utilizar o modelo dipolar em relação ao IGRF-11. Desta maneira, recomenda o uso de um modelo mais realista tal como o IGRF para a obtenção das componentes do campo geomagnético.

\section{CÁlCULO DO STEC}

Os valores do STEC (Slant TEC) podem ser interpolados a partir de um Mapa Global da Ionosfera (GIM - Global Ionosphere Map) (SCHAER; GURTNER, 1998) disponibilizados via internet pelo IGS. Esses mapas possuem estimativa do 
VTEC (Vertical TEC) em um grid com dimensões de dois graus de latitude por cinco de longitude num intervalo de tempo de duas horas. Têm-se também os mapas regionais tal como o Modelo Ionosférico de La Plata (LPIM), o qual faz parte atualmente da rede SIRGAS-CON (BRUNINI, et al., 2007). No caso de receptores de dupla frequência, os valores de STEC podem ser calculados utilizando as pseudodistâncias e ou fase da onda portadora, juntamente com os valores de atrasos de hardware nas frequências L1 e L2, os quais ao serem combinados para os códigos são chamados de DCBs (Differential Code Bias).

As equações de pseudodistâncias para as duas frequências (L1 e L2), considerando o código P, ou seja, P1 e P2, juntamente com os efeitos de primeira ordem da ionosfera e as componentes do atraso de hardware do receptor e do satélite, podem ser escritas como:

$$
\begin{aligned}
& \mathrm{PD}_{\mathrm{rL} 1}^{\mathrm{s}}=\rho_{\mathrm{r}}^{\mathrm{s}}+\mathrm{c} \cdot\left[\mathrm{dt}_{\mathrm{r}}-\mathrm{dt}^{\mathrm{s}}\right]+\mathrm{c} \cdot \mathrm{b}_{\mathrm{rL1}}+\mathrm{c} \cdot \mathrm{b}_{\mathrm{L} 1}^{\mathrm{s}}+\mathrm{I}_{\mathrm{gL} 1}^{(1)}+v_{\mathrm{PD}}^{\mathrm{s}}{ }_{\mathrm{rL1}} \\
& \mathrm{PD}_{\mathrm{rL} 2}^{\mathrm{s}}=\rho_{\mathrm{r}}^{\mathrm{s}}+\mathrm{c} \cdot\left[\mathrm{dt}_{\mathrm{r}}-\mathrm{dt}^{\mathrm{s}}\right]+\mathrm{c} \cdot \mathrm{b}_{\mathrm{rL} 2}+\mathrm{c} \cdot \mathrm{b}_{\mathrm{L} 2}^{\mathrm{s}}+\mathrm{I}_{\mathrm{gL} 2}^{(1)}+\mathrm{v}_{\mathrm{PD}_{\mathrm{rL} 2}^{\mathrm{s}}}
\end{aligned}
$$

Na Equação $14 \rho_{\mathrm{r}}^{\mathrm{s}}$ é distância geométrica entre o receptor $\mathrm{r}$ e o satélite s; c é a velocidade da luz no vácuo; $\mathrm{dt}_{\mathrm{r}} \mathrm{e} \mathrm{dt}^{\mathrm{s}}$ representam os erros do relógio do receptor e do satélite, respectivamente; $b_{r k} e b^{s}{ }_{k}$ são os atraso de hardware do receptor e do satélite, respectivamente para $(\mathrm{k}=1,2)$ e finalmente $\mathrm{v}_{\mathrm{PD}_{\mathrm{rk}}^{\mathrm{s}}}$ representa os demais efeitos não modelados na pseudodistância. No caso da Equação 14, utiliza-se o código P1 para a frequência $\mathrm{L} 1$. Na ausência dessa medida, pode-se utilizar o código C/A, bastando aplicar a correção do DCB (P1-C1) para tornar a medida C/A consistente com a medida P1. Substituindo o efeito ionosférico de primeira ordem (Equações 12) nas Equações 14 e aplicando a combinação livre da geometria ( $\mathrm{PD}_{\mathrm{r} \mathrm{si}}^{\mathrm{s}}=\mathrm{PD}_{\mathrm{rL1}}^{\mathrm{s}}-\mathrm{PD}_{\mathrm{r} L 2}^{\mathrm{s}}$ ), o cálculo do STEC é dado por (CIRAOLO et al., 2007; MATSUOKA; CAMARGO, 2004):

$$
\mathrm{STEC}=\frac{\mathrm{f}_{\mathrm{L} 1}^{2} \cdot \mathrm{f}_{\mathrm{L} 2}^{2}}{40,309 \cdot\left(\mathrm{f}_{\mathrm{L} 2}^{2}-\mathrm{f}_{\mathrm{L} 1}^{2}\right)}\left[\mathrm{PD}_{\mathrm{rL} 1}^{\mathrm{s}}-\mathrm{PD}_{\mathrm{rL} 2}^{\mathrm{s}}-\mathrm{c} \cdot \mathrm{DCB}_{\mathrm{r}}-\mathrm{c} \cdot \mathrm{DCB}^{\mathrm{s}}+\varepsilon_{\mathrm{PD}_{\mathrm{L} 1 \mathrm{~L} 2}}\right] .
$$

Se forem utilizadas as pseudodistâncias P1 e P2 filtradas pela fase na Equação 15 obtém-se valores do STEC com menor nível de ruído do que ao utilizar as pseudodistâncias originais. Neste caso, algoritmos de filtragem da pseudodistância pela fase podem ser encontrados, por exemplo, em HOFMANN-WELLENHOF; LICHTENEGGER; COLLINS (1992) e LEICK (2004) e outros. Ao utilizar este tipo de filtragem a ambiguidade é eliminada devido à aplicação de diferenças entre 
medidas em consecutivas épocas desde que não ocorram perdas de ciclos. É importante dizer que alguns autores geralmente utilizam o termo pseudodistância suavizada pela fase, porém neste trabalho utilizou-se o termo filtrada ao invés de suavizada. No caso, está se considerando que o STEC é calculado a vante (forward) num processo recursivo, onde se faz primeiramente uma predição e em seguida a filtragem. Outra maneira de estimar o STEC é a partir da combinação ionosférica de fase e de pseudodistância, procedimento este conhecido como pseudodistância nivelada pela fase (code levelled by carrier phase), como pode ser visto na Equação 16 (IERS, 2010).

$$
\begin{aligned}
& \phi_{\mathrm{r} L i}^{\mathrm{s}}=\lambda_{\mathrm{L} 1} \phi_{\mathrm{r} L 1}^{\mathrm{s}}-\lambda_{\mathrm{L} 2} \phi_{\mathrm{r} L 2}^{\mathrm{s}}, \\
& \mathrm{PD}_{\mathrm{r} \mathrm{Li}}^{\mathrm{s}}=\mathrm{PD}_{\mathrm{r} \mathrm{L} 1}^{\mathrm{s}}-\mathrm{PD}_{\mathrm{r} \mathrm{L} 2}^{\mathrm{s}},
\end{aligned}
$$

em que, $\phi_{\mathrm{rLi}}^{\mathrm{s}}$ e $\mathrm{PD}_{\mathrm{rLi}}^{\mathrm{s}}$ representam, respectivamente, a combinação ionosférica para fase e código na frequência $f_{i}$ em metros. A combinação ionosférica para a pseudodistância é realizada utilizando as Equações 14, enquanto para o caso da fase comparece a ambiguidade.

$$
\phi_{\mathrm{rLi}}^{\mathrm{s}}=\lambda_{\mathrm{L} 1} \phi_{\mathrm{rL} 1}^{\mathrm{s}}-\lambda_{\mathrm{L} 2} \phi_{\mathrm{rL} 2}^{\mathrm{s}}=\frac{40,309 \cdot\left(\mathrm{f}_{\mathrm{L} 1}^{2}-\mathrm{f}_{\mathrm{L} 2}^{2}\right)}{\mathrm{f}_{\mathrm{L} 1}^{2} \cdot \mathrm{f}_{\mathrm{L} 2}^{2}} \mathrm{STEC}+\lambda_{\mathrm{Li}} \mathrm{Ni}+\varepsilon_{\phi_{\mathrm{LIL} 2}},
$$

em que, $\lambda_{\mathrm{Li}} \mathrm{Ni}(\mathrm{m})$ é a ambiguidade da combinação ionosférica para fase juntamente com os atrasos de hardware e outros. A ambiguidade Ni pode ser estimada a partir da diferença entre a combinação ionosférica de pseudodistância e fase $\mathrm{Ni}=\phi_{\mathrm{i}}-\mathrm{PD}_{\mathrm{i}}$ de forma que o STEC pode ser calculado por:

$$
\mathrm{STEC}=\frac{\mathrm{f}_{\mathrm{L} 1}^{2} \cdot \mathrm{f}_{\mathrm{L} 2}^{2}}{40,309 \cdot\left(\mathrm{f}_{\mathrm{L} 1}^{2}-\mathrm{f}_{\mathrm{L} 2}^{2}\right)}\left[\phi_{\mathrm{rLi}}^{\mathrm{s}}-\mathrm{PD}_{\mathrm{rLi}}^{\mathrm{s}}-\left\langle\phi_{\mathrm{rLi}}^{\mathrm{s}}-\mathrm{PD}_{\mathrm{rLi}}^{\mathrm{s}}\right\rangle+\mathrm{c} \cdot \mathrm{DCB}_{\mathrm{r}}+\mathrm{c} \cdot \mathrm{DCB}^{\mathrm{s}}\right]
$$

O termo $\left\langle\phi_{\mathrm{r} L i}^{\mathrm{s}}-\mathrm{PD}_{\mathrm{rLi}}^{\mathrm{s}}\right\rangle$ na Equação 18 representa a estimativa pela média da ambiguidade da fase para um arco de dados GNSS sem perdas de ciclos. Este tipo de combinação é ideal para pós-processamento de dados, onde se calculam os valores de ambiguidades que são posteriormente aplicados no calculo do STEC. No caso de perda de ciclo, pode-se adotar a estratégia de corrigir os dados da perda de ciclo ou simplesmente reiniciar a estimativa das ambiguidades para um novo arco de dados.

Em trabalhos anteriores, tais como Marques et al. (2009) e Marques; Monico e Aquino (2011) o cálculo de STEC foi baseado na pseudodistância filtrada pela fase e interpolação a partir do GIM. Nesta contribuição foi apresentada também o 
calculo do STEC a partir da pseudodistância nivelada pelo código, onde se estima a ambiguidade da fase para um arco de dados GPS e posteriormente aplica-se a ambiguidade para o cálculo do STEC. Esta tarefa pode ser pensada como um processo de suavização (backward substitution) dentro do conceito de estimativa por Filtro de Kalman, considerando que se estima um parâmetro recursivamente e posteriormente este é aplicado a partir do inicio da série temporal para a estimativa de novos parâmetros.

\subsection{Análise do STEC a Partir dos Diferentes Métodos}

Os valores de STEC foram obtidos a partir das diferentes formas apresentadas na seção 3, ou seja, interpolação a partir do mapa global GIM, cálculo utilizando a pseudodistância pura, pseudodistância filtrada pela fase e finalmente a partir da pseudodistância nivelada pela fase com estimativa das ambiguidades. Os dados GPS se referem ao dia 231 de 2007 coletados na estação BRFT pertencente à RBMC (Rede Brasileira de Monitoramento Contínuo). A Figura 5 mostra a série temporal típica do STEC calculado para os satélites PRN11 e PRN 17.

Figura 5 - STEC para os satélites PRN11 e PRN17.

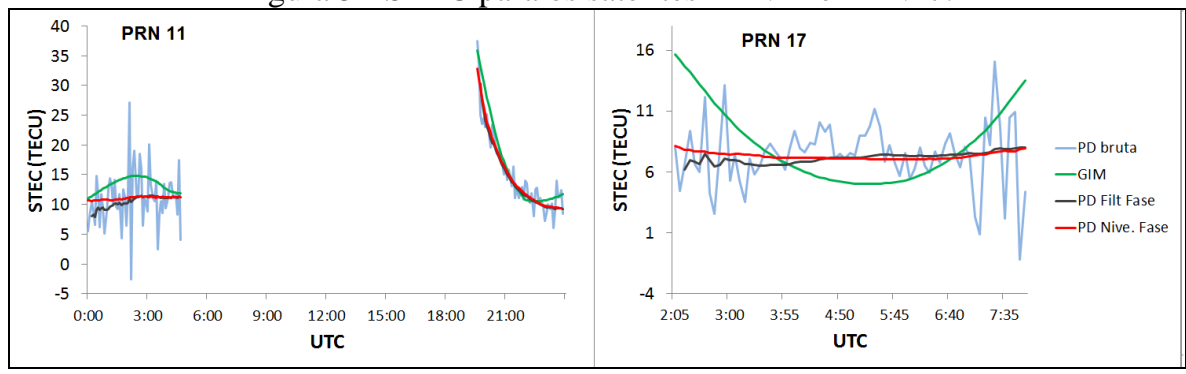

Enquanto o STEC a partir da pseudodistância pura apresenta alto nível de ruído, verifica-se que com a pseudodistância filtrada pela fase e com a pseudodistância nivelada pela fase, os valores de STEC são bem mais suaves. No último caso, a série temporal do STEC começa com valores mais estáveis, o que está relacionado com o fato de se calcular a ambiguidade da fase para o arco inteiro de dados e posteriormente utilizá-la para o cálculo do STEC.

\section{COMBINAÇÃO TRIPLA FREQUÊNCIA}

Devido a contribuição de primeira ordem da ionosfera ser inversamente proporcional ao quadrado da frequência, pode-se aplicar a combinação livre da ionosfera (ion-free) para eliminação destes efeitos. Logo, quando se tem dados de receptores de dupla frequência (L1 e L2) pode-se formar a seguinte combinação para o caso da fase (em metros): 


$$
\phi_{\mathrm{IF}}^{\left(\mathrm{L}_{1}, \mathrm{~L}_{2}\right)}=\frac{\mathrm{f}_{1}^{2} \phi_{\mathrm{L} 1}+\mathrm{f}_{2}^{2} \phi_{\mathrm{L} 2}}{\left(\mathrm{f}_{1}^{2}-\mathrm{f}_{2}^{2}\right)} \text {. }
$$

A combinação dos efeitos de primeira, segunda e terceira ordem para a fase pode ser escrita com base nas informações da Equação 12:

$$
\Delta \mathrm{I}=-\mathrm{I}_{\mathrm{gLi}}^{(1)}-\frac{1}{2} \mathrm{I}_{\mathrm{gLi}}^{(2)}-\frac{1}{3} \mathrm{I}_{\mathrm{gLi}}^{(3)}=-\frac{\mathrm{s}_{1}}{\mathrm{f}_{\mathrm{i}}^{2}}-\frac{\mathrm{s}_{2}}{\mathrm{f}_{\mathrm{i}}^{3}}-\frac{\mathrm{s}_{3}}{\mathrm{f}_{\mathrm{i}}^{4}}, \quad(\mathrm{i}=1,2,5)
$$

em que, $s_{1}, s_{2}$ e $s_{3}$ contém as componentes independentes da frequência para os efeitos de primeira, segunda e terceira ordem, respectivamente. Desta forma, os efeitos ionosféricos (Equação 20) inseridos na equação ion-free (Equação 19) podem ser escritos como:

$$
\Delta \mathrm{I}_{\mathrm{IF}}^{\left(\mathrm{L}_{1}, \mathrm{~L}_{2}\right)}=\frac{\mathrm{f}_{1}^{2}\left(-\frac{\mathrm{s}_{1}}{\mathrm{f}_{1}^{2}}-\frac{\mathrm{s}_{2}}{\mathrm{f}_{1}^{3}}-\frac{\mathrm{s}_{3}}{\mathrm{f}_{1}^{4}}\right)+\mathrm{f}_{2}^{2}\left(-\frac{\mathrm{s}_{1}}{\mathrm{f}_{2}^{2}}-\frac{\mathrm{s}_{2}}{\mathrm{f}_{2}^{3}}-\frac{\mathrm{s}_{3}}{\mathrm{f}_{2}^{4}}\right)}{\left(\mathrm{f}_{1}^{2}-\mathrm{f}_{2}^{2}\right)}=\frac{\mathrm{s}_{2}}{\mathrm{f}_{1} \mathrm{f}_{2}\left(\mathrm{f}_{1}^{2}+\mathrm{f}_{2}^{2}\right)}+\frac{\mathrm{s}_{3}}{\mathrm{f}_{1}^{2} \mathrm{f}_{1}^{2}} .
$$

Os efeitos de primeira ordem são eliminados restando somente os efeitos de segunda e terceira ordem. Considerando a portadora $\mathrm{L}_{5}$ do GPS, pode-se aplicar a combinação livre da ionosfera para $\mathrm{L}_{2}$ e $\mathrm{L}_{5}$, como mostra a Equação 22.

$$
\phi_{\mathrm{IF}}^{\left(\mathrm{L}_{2}, \mathrm{~L}_{5}\right)}=\frac{\mathrm{f}_{2}^{2} \phi_{\mathrm{L} 2}+\mathrm{f}_{5}^{2} \phi_{\mathrm{L} 5}}{\left(\mathrm{f}_{2}^{2}-\mathrm{f}_{5}^{2}\right)} .
$$

$\mathrm{O}$ erro resultante da ionosfera na combinação para $\mathrm{L}_{2}$ e $\mathrm{L}_{5} \quad \Delta \mathrm{I}_{\mathrm{IF}}^{\left(\mathrm{L}_{2}, \mathrm{~L} 5\right)}$ é semelhante ao apresentado na Equação 21. A partir da combinação livre da ionosfera entre os dois conjuntos de frequência $\phi_{\mathrm{IF}}^{\left(\mathrm{L}_{1}, \mathrm{~L}_{2}\right)}$ e $\phi_{\mathrm{IF}}^{\left(\mathrm{L}_{2}, \mathrm{~L}_{5}\right)}$, uma nova combinação é gerada de forma a eliminar os efeitos de segunda ordem como mostrado na Equação 23 (IERS, 2010, p. 146):

$$
\phi_{\mathrm{IF}}^{\left(\mathrm{L}_{1}, \mathrm{~L}_{2}, \mathrm{~L}_{5}\right)}=\frac{\mathrm{f}_{1} \mathrm{f}_{2}\left(\mathrm{f}_{1}+\mathrm{f}_{2}\right) \phi_{\mathrm{IF}}^{\left(\mathrm{L}_{1}, \mathrm{~L}_{2}\right)}-\mathrm{f}_{2} \mathrm{f}_{5}\left(\mathrm{f}_{2}+\mathrm{f}_{5}\right) \phi_{\mathrm{IF}}^{\left(\mathrm{L}_{2}, \mathrm{~L}_{5}\right)}}{\mathrm{f}_{1} \mathrm{f}_{2}\left(\mathrm{f}_{1}+\mathrm{f}_{2}\right)-\mathrm{f}_{2} \mathrm{f}_{5}\left(\mathrm{f}_{2}+\mathrm{f}_{5}\right)} .
$$

Reorganizando a Equação 23 em termos das observáveis básicas em L1, L2 e L5, tem-se: 


$$
\phi_{\mathrm{IF}}^{\left(\mathrm{L}_{1}, \mathrm{~L}_{2}, \mathrm{~L}_{5}\right)}=\frac{1}{\mathrm{f}_{1}+\mathrm{f}_{2}+\mathrm{f}_{5}}\left(\frac{\mathrm{f}_{1}^{3} \phi_{\mathrm{L}_{1}}}{\left(\mathrm{f}_{1}-\mathrm{f}_{2}\right)\left(\mathrm{f}_{1}-\mathrm{f}_{5}\right)}+\frac{\mathrm{f}_{2}^{3} \phi_{\mathrm{L}_{2}}}{\left(\mathrm{f}_{2}-\mathrm{f}_{1}\right)\left(\mathrm{f}_{2}-\mathrm{f}_{5}\right)}+\frac{\mathrm{f}_{5}^{3} \phi_{\mathrm{L}_{5}}}{\left(\mathrm{f}_{5}-\mathrm{f}_{1}\right)\left(\mathrm{f}_{5}-\mathrm{f}_{2}\right)}\right)
$$

Fazendo as seguintes correspondências

$$
\begin{aligned}
& \mathrm{m}_{1}=\frac{\mathrm{f}_{1}^{3}}{\left(\mathrm{f}_{1}+\mathrm{f}_{2}+\mathrm{f}_{5}\right)\left[\left(\mathrm{f}_{1}-\mathrm{f}_{2}\right)\left(\mathrm{f}_{1}-\mathrm{f}_{5}\right)\right]}, \\
& \mathrm{m}_{2}=\frac{\mathrm{f}_{2}^{3}}{\left(\mathrm{f}_{1}+\mathrm{f}_{2}+\mathrm{f}_{5}\right)\left[\left(\mathrm{f}_{2}-\mathrm{f}_{1}\right)\left(\mathrm{f}_{2}-\mathrm{f}_{5}\right)\right]}, \\
& \mathrm{m}_{5}=\frac{\mathrm{f}_{5}^{3}}{\left(\mathrm{f}_{1}+\mathrm{f}_{2}+\mathrm{f}_{5}\right)\left[\left(\mathrm{f}_{5}-\mathrm{f}_{1}\right)\left(\mathrm{f}_{5}-\mathrm{f}_{2}\right)\right]} .
\end{aligned}
$$

e correlacionando as Equações 25, 26 e 27 com a Equação 24, tem-se:

$$
\phi_{\mathrm{IF}}^{\left(\mathrm{L}_{1}, \mathrm{~L}_{2}, \mathrm{~L}_{5}\right)}=\mathrm{m}_{1} \phi_{\mathrm{L}_{1}}+\mathrm{m}_{2} \phi_{\mathrm{L}_{2}}+\mathrm{m}_{5} \phi_{\mathrm{L}_{5}}
$$

Considerando a precisão das observáveis originais $\sigma_{\phi_{L_{1}}}, \sigma_{\phi_{L_{2}}}$ e $\sigma_{\phi_{L_{5}}}$, a precisão da combinação livre dos efeitos de primeira e segunda ordem da ionosfera pode ser obtida via propagação de covariâncias utilizando a Equação 28, obtendose:

$$
\sigma_{\left.\phi_{\mathrm{IF}}, \mathrm{L}_{1}, \mathrm{~L}_{2}, \mathrm{~L}_{5}\right)}=\sqrt{\mathrm{m}_{1}^{2} \sigma_{\phi_{\mathrm{L}_{1}}}^{2}+\mathrm{m}_{2}^{2} \sigma_{\phi_{\mathrm{L}_{2}}}^{2}+\mathrm{m}_{5}^{2} \sigma_{\phi_{\mathrm{L}_{5}}}^{2}}
$$

Dados os valores das frequências para o caso do GPS: $f_{1}=1575,42 \mathrm{MHz}$; $\mathrm{f}_{2}=1227,60 \mathrm{MHz}$ e $\mathrm{f}_{5}=1176,45 \mathrm{MHz}$, os valores dos coeficientes da combinação são dados por: $\mathrm{m} 1=7,081 ; \mathrm{m} 2=-26,130$ e $\mathrm{m} 5=20,050$. Considerando as medidas GPS nas três frequências com sendo de mesma precisão, verifica-se facilmente a partir da Equação 29 que a precisão da combinação de tripla frequência fica degradada aproximadamente 34 vezes com relação à precisão da medida original.

O nível de ruído da fase nas portadoras do GPS pode atingir valores de 0,5 a 2 mm (MCDONALD, 2002). Considerando então o valor de $2 \mathrm{~mm}$ para a precisão das observáveis em cada portadora, verifica-se a partir da Equação 29 que a precisão da combinação é de aproximadamente $7 \mathrm{~cm}$.

É importante também levar em consideração que no processamento dos dados GNSS, geralmente, os softwares adotam uma estratégia de ponderação da variância das observações em função do ângulo de elevação (E) do satélite ao calcular a matriz dos pesos. Estratégias de ponderação para o cálculo dos pesos foram discutidas em Silva et al. (2010) sendo uma delas dadas pelo inverso do seno do ângulo de elevação. Adotando esta estratégia de ponderação, foram calculados os 
ângulos de elevação para os satélites GPS utilizando os dados de navegação do dia 295 de 2012 da estação RECF e obtidos as precisões ponderadas como mostrado na Figura 6.

Figura 6 - Ângulo de elevação dos satélites e precisão (L1, L2 e L5) ponderada.

\begin{tabular}{|c|c|c|}
\hline 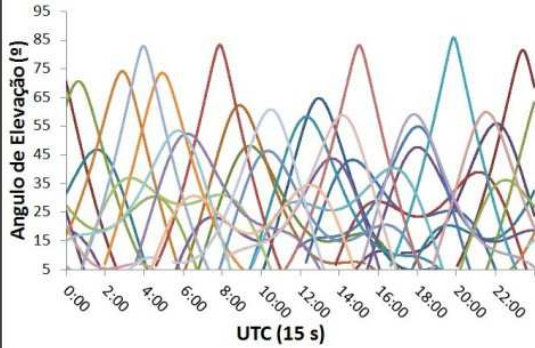 & 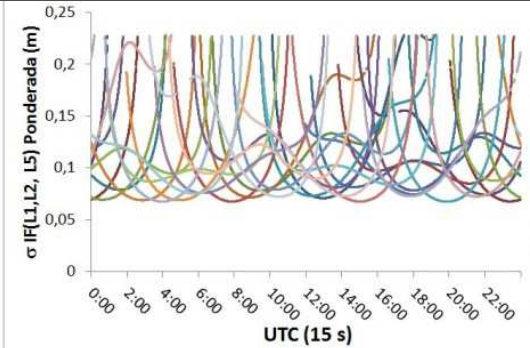 & 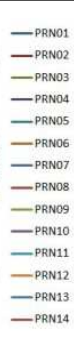 \\
\hline
\end{tabular}

Para ângulo de elevação dos satélites de até 5 graus o valor da precisão ponderada da combinação ion-free (L1, L2 e L5) atinge a ordem de aproximadamente $22 \mathrm{~cm}$ como pode ser observado na Figura 6.

\section{AVALIAÇÃO DOS EFEITOS IONOSFÉRICOS DE ORDEM SUPERIOR NO CICLO SOLAR 24}

Os valores dos efeitos de segunda e terceira ordem da ionosfera foram calculados com o software RINEX_HO (MARQUES et al, 2011) para o período envolvendo os anos de 2006 até 2013,8, os quais fazem parte do ciclo solar 24. A Figura 7 apresenta o valor máximo diário do efeito ionosférico de segunda ordem (I2) na direção receptor satélite para a frequência L1. Os valores foram calculados para a estação RECF da RBMC.

Figura 7 - Máximo I2 diário (L1) para os anos 2006 a 2013,8.

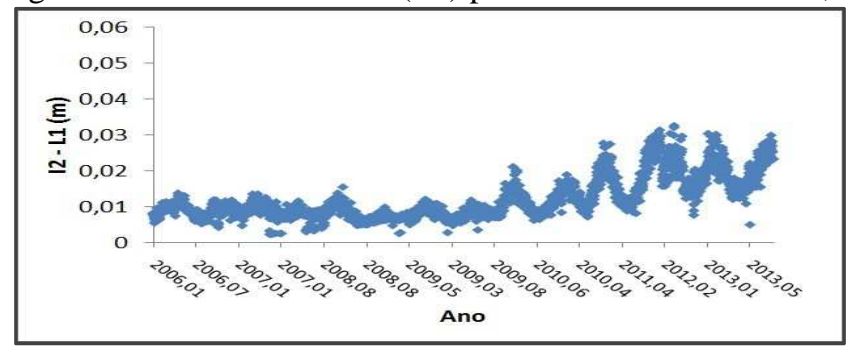

O máximo valor encontrado foi para o ano de 2012 sendo aproximadamente de $3,5 \mathrm{~cm}$. Verifica-se na Figura 7 o aumento dos valores de I 2 em função da atividade do ciclo solar. A magnitude dos efeitos ionosférico nas portadoras L2 e L5 pode ser 
obtida multiplicando os valores de $\mathrm{I} 2$ (L1) pelos fatores de escala $\left(\mathrm{f}_{1} / \mathrm{f}_{2}\right)^{2}$ e $\left(\mathrm{f}_{1} / \mathrm{f}_{5}\right)^{2}$, respectivamente. Logo, para o caso da portadora $L 5$, os valores dos efeitos de segunda ordem são mostrados na Figura 8.

Figura 8 - Máximo I2 diário (L5) para os anos 2006 a 2013,8.

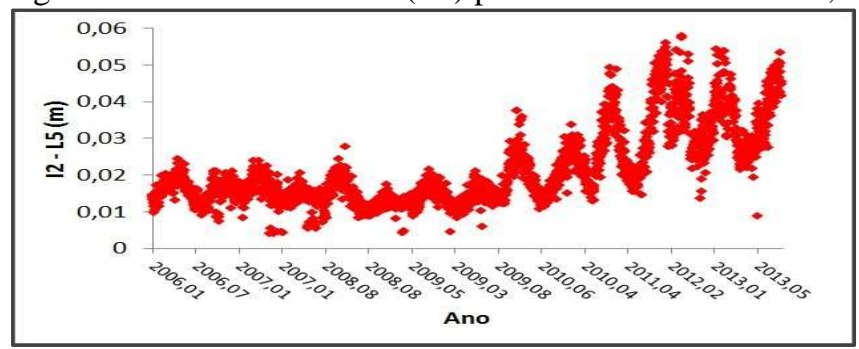

O máximo diário do efeito de segunda ordem encontrado para a portadora L5 foi de aproximadamente $6 \mathrm{~cm}$ para o ano de 2012 conforme pode ser visto na Figura 8. Verifica-se que o máximo valor da incerteza da combinação ion-free de tripla frequência (Figura 6) é aproximadamente três vezes maior que o máximo valor de do efeito de segunda ordem encontrado na portadora L5 (Figura 8), comprovando que a correção deste efeito a partir de modelo matemático é mais adequada do que o uso da combinação de tripla frequência.

A variação diária dos efeitos ionosféricos de ordem superior (segunda ordem - I2 e terceira ordem - I3) será apresentada para o dia 295 do ano de 2006 (22/10/2006) e 295 de 2012 (21/10/2012), respectivamente. Esses dias foram escolhidos de forma aleatória, contudo procurou-se escolher o mesmo dia para anos de baixa e de alta atividade solar, respectivamente. A Figura 9 mostra o fluxo de raios X para os dias 295 do ano 2006 e 2012.

Figura 9 - Fluxo de raios X para o dia 295 de 2006 (esquerda) e 2012 (direita).

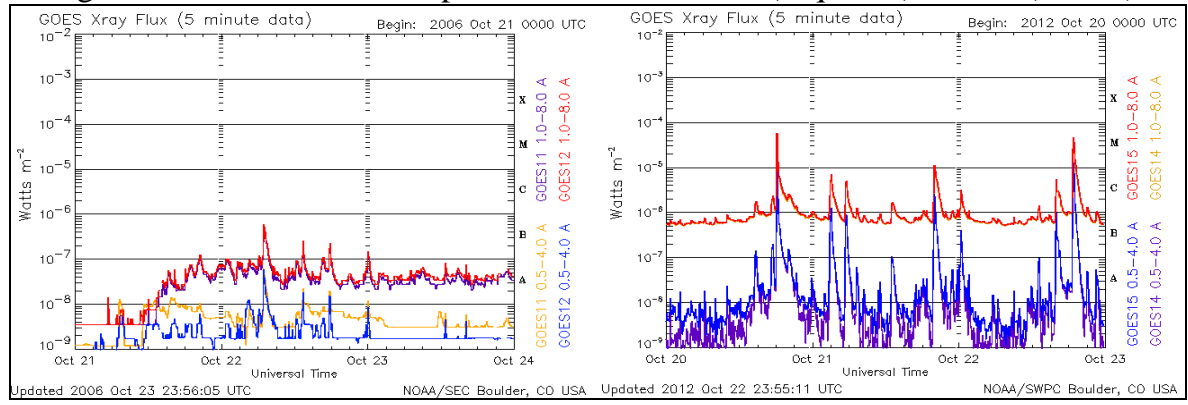


As explosões solares são classificadas de acordo com o fluxo de raios $\mathrm{X}$ sendo a magnitude em X (grande), M (média) e C (pequena). Na Figura 9, verificase que para o ano de 2006 (gráfico a esquerda) o fluxo de raios $\mathrm{X}$ atingiu no máximo a classe B indicando baixa atividade solar. Para o caso do ano de 2012 (gráfico a direita na Figura 9), o fluxo de raios X atingiu a classe C no dia 295 podendo ocorrer pequenas explosões solares (MARQUES, 2013).

A variação diária do STEC (Slant TEC) para os dias 295 de 2006 e 2012 é apresentada na Figura 10.

Figura 10 - STEC para os dias 295 de 2006 e 2012.

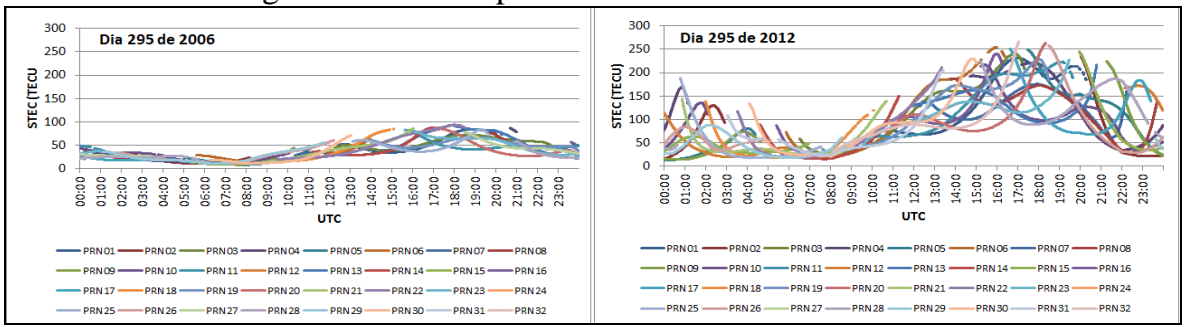

Verifica-se na Figura 10 que a variação o STEC máximo foi da ordem de 100 TECU para o ano de 2006 enquanto que para o ano de 2012, o máximo STEC foi da ordem de 250 TECU.

A variação diária dos efeitos ionosféricos de $2^{\mathrm{a}}$ e $3^{\mathrm{a}}$ ordem para os dias 295 de 2006 e 2012 pode ser vista nas Figuras 11 e 12.

Figura 11 - Variação diária (I2_L1) para o dia 295 dos anos 2006 e 2012.

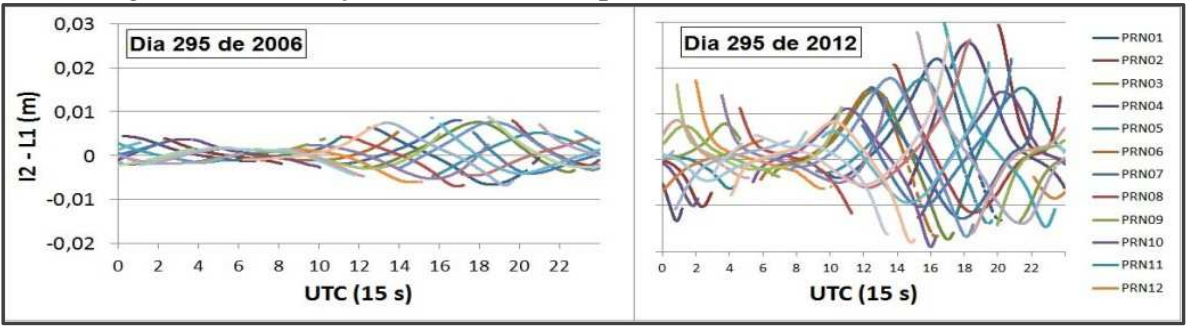

Figura 12 - Variação diária (I3_L1) para o dia 295 dos anos 2006 e 2012.

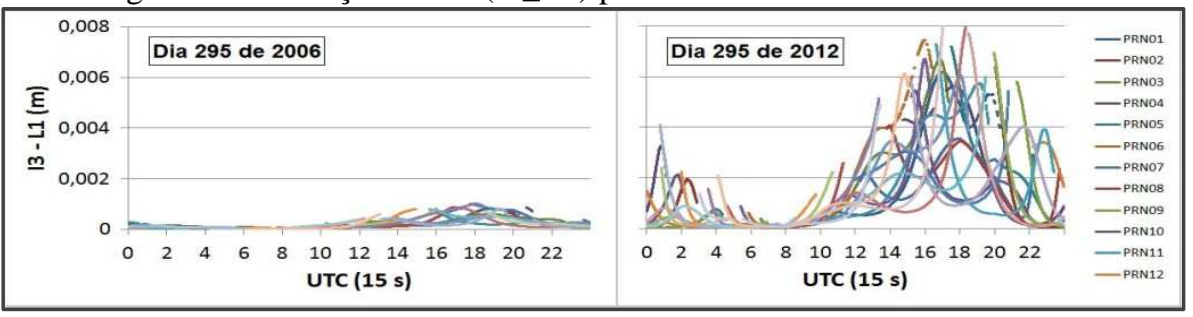

Bol. Ciênc. Geod., sec. Artigos, Curitiba, v. 20, no 4, p.879-901, out-dez, 2014. 
Os efeitos ionosféricos de $2^{\mathrm{a}}$ e $3^{\mathrm{a}}$ ordem atingiram, respectivamente, valores máximos de 0,01 m e 0,001 m no dia 295 de 2006. Já para o caso do dia 295 de $2012 \mathrm{com}$ maior atividade ionosférica, os efeitos de $2^{\mathrm{a}}$ e $3^{\mathrm{a}}$ ordem atingiram máximo de $0,03 \mathrm{~m}$ e $0,008 \mathrm{~m}$, respectivamente.

\section{INFLUÊNCIA DOS EFEITOS IONOSFÉRICOS DE ORDEM SUPERIOR NO PPP}

Os processamentos de dados GPS no modo PPP foi realizado com o software RT_PPP (MARQUES, 2012). A partir deste software é possível realizar PPP estático ou cinemático utilizando dados de dupla frequência com modelagem matemática dos diversos efeitos envolvidos no posicionamento GNSS, tais como: estimativa da troposfera, carga de marés oceânicas, marés de corpos terrestres, efeitos de relatividade, correção absoluta do centro de fase das antenas do receptor e satélite entre outros.

Foram processados dados da estação RECF no modo PPP estático com soluções diárias para o ano de 2011. Para correção dos efeitos de primeira ordem da ionosfera aplicou-se a combinação ion-free, enquanto os efeitos de segunda e terceira ordem da ionosfera foram corrigidos utilizando o software RINEX_HO. Para verificar a influência dos efeitos de ordem superior da ionosfera, as coordenadas estimadas a partir de dados GPS corrigidos foram comparadas com aquelas estimadas a partir de dados GPS sem correção. Dessa maneira, define-se o "erro" no PPP devido a não correção dos efeitos de ordem superior da ionosfera. A Figura 13 mostra os erros no SGL (Sistema Geodésico Local) devido a estes efeitos na solução diária para o ano de 2011.

Figura 13 - "Erro" no PPP estático devido a não correção do efeito de ordem

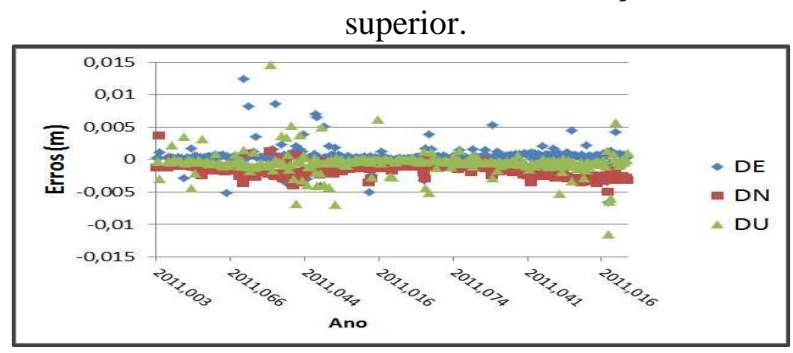

A Tabela 1 mostra o máximo anual e o EMQ (Erro Médio Quadrático) relacionados ao PPP estático para todo o período do ano de 2011.

Tabela 1 - Máximo anual e EMQ para o PPP estático

\begin{tabular}{c|c|c|c|c}
\hline & $\mathrm{DE}(\mathrm{m})$ & $\mathrm{DN}(\mathrm{m})$ & $\mathrm{DU}(\mathrm{m})$ & Resultante $(\mathrm{m})$ \\
\hline Máximo Anual & 0,012 & 0,004 & 0,015 & \\
\hline EMQ & 0,0016 & 0,0020 & 0,0019 & 0,0032 \\
\hline
\end{tabular}


O erro máximo anual atingiu a ordem de $0,015 \mathrm{~m}$ na componente altimétrica e o EMQ resultante foi de aproximadamente $0,003 \mathrm{~m}$ para o ano de 2011. Os dados também foram processados no modo cinemático com o objetivo de verificar a variação diária no PPP.

Foram processados os dados do dia 11 de março de 2011, sendo que neste dia o índice $\mathrm{Kp}$ atingiu a ordem de 4 com fluxo de raios $\mathrm{X}$ na classe $\mathrm{M}$, indicando atividade ionosférica com possibilidade de explosões solares medias. Os erros no PPP cinemático devido a não correção dos efeitos de ordem superior da ionosfera podem ser visto na Figura 14

Figura 14 - "Erro" no PPP cinemático devido a não correção do efeito de ordem superior.

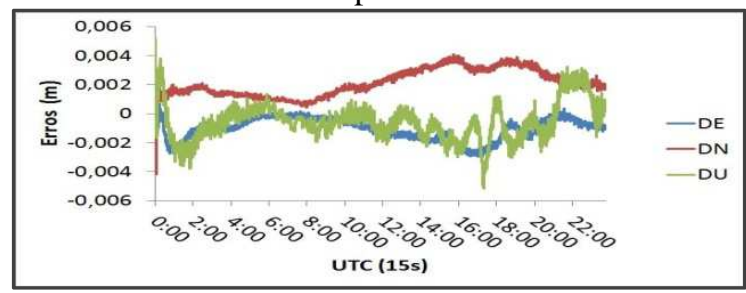

A Tabela 2 mostra o máximo diário e EMQ de todo o período relacionado ao PPP cinemático para o dia 11 de março de 2011.

Tabela 2 - Máximo anual e EMQ para o PPP cinemático

\begin{tabular}{c|c|c|c|c}
\hline & $\mathrm{DE}(\mathrm{m})$ & $\mathrm{DN}(\mathrm{m})$ & $\mathrm{DU}(\mathrm{m})$ & Resultante $(\mathrm{m})$ \\
\hline Máximo Diário & 0,0013 & 0,0041 & 0,0052 & \\
\hline EMQ & 0,0013 & 0,0023 & 0,0014 & 0,003 \\
\hline
\end{tabular}

O erro máximo devido a não correção dos efeitos de ordem superior da ionosfera atingiu aproximadamente $0,005 \mathrm{~m}$ em altimetria com EMQ resultante de $0,003 \mathrm{~m}$. Quando se trata de solução das ambiguidades no PPP, um assunto objeto de investigação da comunidade científica na atualidade, a não correção dos efeitos de ordem superior da ionosfera pode causar influência, uma vez que a utilização de medidas não corrigidas afeta a estimativa dos parâmetros envolvidos no PPP.

\section{CONCLUSÕES}

Este trabalho abordou o tema relacionado com os efeitos de ordem superior da ionosfera, sendo apresentadas as equações para o cálculo dos efeitos de segunda e terceira ordem da ionosfera, além de discussões relacionadas ao cálculo do STEC, campo geomagnético a partir do IGRF-11 e utilização da terceira frequência (L5) do GPS para eliminação dos efeitos de segunda ordem. As correções podem ser 
aplicadas a partir do software RINEX_HO disponível na homepage do NGSNOAA-Toolbox.

Os efeitos de ordem superior quando não corrigidos no posicionamento GNSS, provocam estimativa tendenciosa das coordenadas das estações atingindo a ordem de milímetros podendo chegar a centímetros. Para o caso de estimativa de coordenadas para estações de referência em redes geodésicas estes efeitos não foram corrigidos até o momento, seja no âmbito nacional ou internacional. Dentro deste contexto, o IERS Conventions 2010 recomenda aos centros de processamento de dados GNSS e outros que apliquem as correções dos efeitos de ordem superior da ionosfera, algo que provavelmente fará parte das próximas realizações do ITRF.

Verifica-se que o uso da combinação ion-free de tripla frequência permite eliminar os efeitos de segunda ordem da ionosfera (seção 4), contudo a incerteza da combinação é maior que os efeitos de segunda ordem calculados a partir de modelos matemáticos, principalmente para satélites a baixo ângulo de elevação.

Para regiões onde se tem pouca cobertura de estações envolvidas na estimativa de STEC para compor os mapas globais da ionosfera (GIM) é recomendável o cálculo do STEC a partir de medidas GNSS coletadas na estação. O uso de pseudodistância filtrada pela fase foi aplicado em trabalhos anteriores (MARQUES et al., 2009) para o cálculo dos efeitos de ordem superior da ionosfera. Nesta contribuição apresentou-se o cálculo pela combinação conhecida como pseudodistância nivelada pela fase, na qual se estima o parâmetro ambiguidade da fase para um arco de dados GNSS e posteriormente aplica-se este parâmetro no cálculo do STEC. Os resultados são mais estáveis no começo da série temporal do STEC em função de se iniciar com uma ambiguidade de melhor qualidade estimada para o arco de dados. A aplicação do IGRF-11 contra um modelo dipolar do campo geomagnético mostrou que o cálculo dos efeitos de segunda ordem pode atingir diferenças de até $50 \%$ de forma que é recomendada a utilização de um campo geomagnético considerado mais realista tal como o IGRF.

A avaliação dos efeitos para o ciclo solar 24 mostrou que o efeito máximo diário de segunda ordem atingiu aproximadamente $3,5 \mathrm{~cm}$ para a frequência $\mathrm{L} 1 \mathrm{e}$ aproximadamente $6 \mathrm{~cm}$ para a nova portadora L5. Para o caso dos efeitos de terceira ordem, o máximo atinge aproximadamente $1 \mathrm{~mm}$ em período de baixa atividade solar. Contudo em período com maior atividade solar como foi o caso do ano de 2012, os valores dos efeitos de terceira ordem atingiram a aproximadamente $8 \mathrm{~mm}$. Em termo de aplicação no PPP estático, os efeitos de segunda e terceira ordem da ionosfera provocaram efeito máximo de aproximadamente $1,5 \mathrm{~cm}$ nas coordenadas da estação para a série temporal do ano de 2011. No caso do PPP cinemático, o efeito máximo diário foi de aproximadamente $5 \mathrm{~mm}$ com EMQ resultante de $3 \mathrm{~mm}$.

\section{REFERÊNCIAS BIBLIOGRÁFICAS}

BASSIRI, S.; HAJJ, G. A. Higher-order ionospheric effects on the global positioning systems observables and means of modeling them, Manuscr. Geod., 18, 280-289, 1993. 
BRUNNER, F.; GU, M. An improved model for the dual frequency ionospheric correction of GPS observation, Manuscr. Geod., v. 16, p. 205-214, jan. 1991.

BRUNINI C., A. MEZA, M. GENDE, F. AZPILICUETA. South American regional maps of vertical TEC computed by GESA: a service for the ionospheric community. Advances in Space Research, Elsevier, DOI: 10.1016/j.asr.2007.08.04, 2007.

CIRAOLO, L.; AZPILICUETA, F.; BRUNINI, C.; MEZA, A.; RADICELLA, S. M. Calibration errors on experimental slant total electron content (TEC) determined with GPS. Journal of Geodesy. v. 81, n. 2, p. 111-120, fev. 2007.

DAVIES, K. Ionospheric radio. London: Peter Peregrinus Ltd., 1990. 580p.

ELMAS, Z. G.; AQUINO, M.; MARQUES, H. A.; MONICO, J. F. G. Higher order ionospheric effects in GNSS positioning in the European region. Ann. Geophys., 29, 1383-1399, DOI:10.5194/angeo-29-1383-2011, 2011.

FRITSCHE, M.; DIETRICH, R.; KNÖFEL, C.; RÜLKE, A.; VEY, S.; ROTACHER, M.; STEIGENBERGER, P. Impact of higher-order ionospheric terms on GPS estimates, Geophysical Research Letters, v. 32, L23311, DOI:10.29/2005GL024342, 2005.

FERNANDEZ, M. G.; DESAI, S. D.; BUTALA, M. D.; KOMJATHY, A. Evaluation of different approaches to modeling the second-order ionospheric delay on GPS measurements. J. Geophys. Res. Space Physics, DOI: 10.1002/2013JA019356, v. 18, p. 7864-7873, 2013.

PAJARES, H. M.; JUAN, JM., SANZ, .J, ORUS, R.; SALAZAR, D.. Impact and implementation of the second order ionospheric term in GPS positioning (Summary). Barcelona, Spain. Research group of Astronomy and Geomatics Technical University of Catalonia, 23 p, 2005.

PAJARES, H., M.; JUAN, J.; SANZ, J.; ORÚS, R.: Second-order ionospheric term in GPS: Implementation and impact on geodetic estimates, Journal Geophys. Res., Vol. 112, B08417, doi:10.1029/2006JB004707, 2007.

HOFMANN-WELLENHOF, B.; LICHTENEGGER, H. COLLINS, J. GPS: Theory and pratice. 4th. ed. Austria: Springer-Verlag Wien, 1992. 389p.

IERS. IERS Conventions 2010. Disponível em: <http://www.iers.org/IERS/EN/ Publications/TechnicalNotes/tn36.html>. Acesso em Fev. de 2014.

IAGA - International Association of Geomagnetism and Aeronomy. International Geomagnetic Reference Field. Disponível em: <http://www.ngdc.noaa.gov/ IAGA/vmod/igrf.html>. Acesso em Fev. de 2014.

KEDAR S, HAJJ A, WILSON B D, HEFLIN M B. The effect of the second order GPS ionospheric correction on receiver positions, Geophys. Res. Lett., 30(16):1829, 2003.

KLOBUCHAR J. A., C. Ionospheric effects on GPS. In PARKINSON, B. W.; SPILKER JR., J. J. Global Positioning System: Theory and applications. Washington: American Institute of Aeronautics and Astronautics, 1996. v. 2, Cap. 12. 
LEICK, A. GPS satellite surveying. 3rd. ed.: New York: John Wiley \& Sons, 2004. $435 \mathrm{p}$.

MARQUES, H. A; MONICO, J. F. G.; AQUINO, M. ROSA, G. P. S. Efeitos de segunda e terceira ordem da ionosfera no posicionamento GNSS no brasil. Rev. Bras. Geof.. Vol. 27, n 3, 2009.

MARQUES, H. A; MONICO, J. F. G.; AQUINO, M. RINEX_HO: second- and third-order ionospheric corrections for RINEX observation files. In:

GPS Solutions. V. 15, p. 305-314. 2011.

MARQUES, H. A. PPP em tempo real com estimativa das correções dos relógios dos satélites no contexto de rede GNSS. 2012. 245 f. Tese (Doutorado em Ciências Cartográficas) - Faculdade de Ciências e Tecnologia, Universidade Estadual Paulista - Pres. Prudente - SP.

MARQUES, H. A. S. Modelo Estocástico para Dados GNSS e Séries Temporais de Coordenadas GNSS. 2013. 205 f. Tese (Doutorado em Ciências Cartográficas) - Faculdade de Ciências e Tecnologia, Universidade Estadual Paulista - Pres. Prudente - SP.

MCDONALD , K. D. The Modernization of GPS: Plans, New Capabilities and the Future Relationship to Galileo. Journal of Global Positioning Systems. v. 1, n. 1: 1-17. 2002.

MATSUOKA, M. T.; CAMARGO, P. O. Cálculo do TEC usando dados de receptores GPS de dupla frequência para a produção de mapas da ionosfera para a região brasileira. Revista Brasileira de Cartografia. Rio de Janeiro, $\mathrm{n}$. 56/01, p. 14-27, jul. 2004.

MATSUOKA, M. T. Influência de Diferentes Condições da Ionosfera no Posicionamento Por Ponto com GPS: Avaliação na Região Brasileira. 2007. 263 f. Tese (Doutorado em Ciências Cartográficas) - Faculdade de Ciências e Tecnologia, Universidade Estadual Paulista - Pres. Prudente - SP.

NASA, 2014. Solar Cycle Prediction. Disponível em: <http://solarscience.msfc. nasa.gov/predict.shtml>. Acesso em fev. de 2014.

ODIJK D. Fast precise GPS positioning in the presence of ionospheric delays. 2002. 242 f. PhD dissertation, Faculty of Civil Engineering and Geosciences, Delft University of Technology, Delft.

SCHAER, S.; GURTNER, W. IONEX: The Ionosphere Map Exchange Format Version 1. In: Proceedings of the IGS AC Workshop, Darmstadt, p. 9-11, Germany, 1998

SCHUNK, R. W.; NAGY, A. F. Ionosphere: Physics, plasma and chemistry. New York: Cambrigde University Press. 2000. 554p.

SILVA, H. A.; CAMARGO, P. O.; MONICO, J. F. G.; AQUINO, M.; MARQUES, H. A.; DE FRANCESCHI, G, DODSON, A. Stochastic modelling considering ionospheric scintillation effects on GNSS relative and point positioning. In: Advances in Space Research. v. 45, p. 1113-1121. 2010.

(Recebido em julho de 2014. Aceito em agosto de 2014). 